\title{
Synthesis of new generation calix[4]arene derivatives as fluorescence chemosensor and its theoretical calculation
}

\author{
Hacer $A Z A K^{1, * \text { iD }}$ \\ ${ }^{1}$ Karamanoglu Mehmetbey University, Pharmacy Services, 70200, KARAMAN
}

\begin{abstract}
Calixarenes are among the commonly preferred molecules of the supramolecular chemistry since they are easily synthesizable and functionalizable.In this study, new types of calix[4]aren derivatives containing benzylisoquinoline groups were synthesized and the structures of the obtaining compounds were characterized by spectroscopic techniques such as ${ }^{1} \mathrm{H}-\mathrm{NMR},{ }^{13} \mathrm{C}$ NMR. Synthesized calix[4] aren derivatives towards some metal cations $\left(\mathrm{Ag}^{+}, \mathrm{Al}^{+3}, \mathrm{Ba}^{+}, \mathrm{Ca}^{+2}\right.$, $\mathrm{Co}^{+2}, \mathrm{Cs}^{+2}, \mathrm{Fe}^{+3}, \mathrm{Hg}^{+2}, \mathrm{Li}^{+}, \mathrm{Pb}^{+2}, \mathrm{Mg}^{+2}, \mathrm{Mn}^{+2}, \mathrm{Na}^{+}, \mathrm{Cu}^{+2}, \mathrm{Ba}^{+2}, \mathrm{Ni}^{+2}, \mathrm{Zn}^{+2}, \mathrm{Sr}^{+2}$ showed fluorescence behaviors ve these behaviors were investigated utilizing UV-vis spectrophotometer and fluorescence spectroscopic techniques.It was found out according to the obtained results that it got complexed in 1:1 ratio as stoichiometric as a result of its activation with aqueous solutions of $\mathrm{Cu}^{+2}$ and $\mathrm{Fe}^{+2}$ ions and responded as an off-on sensor. In this regard, a highly selective and sensitive sensor was developed. Theoretical studies were also conducted in addition to the achieved experimental results. The bonding of metal ions was also calculated theoretically by using Gaussian 09 and GaussView 5.0.8.
\end{abstract}

\section{Article info \\ History:}

Received:01.06.2019

Accepted:25.10.2019

Keywords:

Calix [4] arene,

Fluorescence Sensor,

Sensor,

DFT

\section{Introduction}

Chemistry plays an important role in subjects such as medicine, biology and environment thanks to the selective signal potential of heavy and transition metal ions. For example; $\mathrm{Fe}(\mathrm{II})$ and $\mathrm{Cu}$ (II) ions $(<1 \mu \mathrm{M})$ take charge in catalysing in biochemical reactions, biological interactions and in intermolecular conduction. However, the accumulation of these ions in the organism in high concentrations cause unhealthy interactions in biochemical reduction-oxidation processes [1-2].

Copper element is the third most common trace element in nature. It presents as $\mathrm{Cu}$ (II) in human body and in natural water. The element of copper is necessary for living cells' maintaining their normal physiological functions in the body. For example, the enzymes, to which the copper element is bound, are of critical importance for electron transitions in mitochondria in humans. Besides copper element's being so important, it is highly poisoning for organisms. The high level of copper, even for a short time, causes gastrointestinal disorders. When it is exposed for a long time, it causes diseases such as Alzheimer, Parkinson, Menkes [3-4]. In the event that there are elements in the organism like $\mathrm{Cu}^{+2}$ which is both an essential element and has toxic characteristics in its redundancy, the concentration of these metals in the organism must immediately be determined. For this reason, determining their accurate amount in any sample is of great importance in terms of both biologic and clinical aspects [5-6]. Atomic absorption and emission-based analytical methods are generally used for such amount detections. If it is given example for these methods, fluorescence-based sensor systems have many advantages such as sensitivity, selectivity, cheapness, ease of use within chemosensor methods such as AAS, electrochemical, colourimetric etc. [7-8]. There must be a suitable ionophore group for the basic design of fluorescence-based sensor systems and to bind the selective ion. Bound ionophore groups cause change in fluorescence emission values. They have a measurable ability to generate signals against the ions to which molecules show selectivity by means of this bonding [9]. Recent studies have focused on the development of fluorescence-based sensor systems in high sensitivity and selectivity for the detection of heavy metal ions. This method is of importance in terms of preparing sample without requiring pretreatment, analysing in a shorter time and preventing the molecules that may make entrepreneurship effect. Because it becomes detectable with fluorimeter or fluorescence microscopes as a result of the activation 
between non-fluorescent and molecules that are fluorescence. It makes extinction fluorescent intensity when bound with fluorophore groups due to the paramagnetic properties of $\mathrm{Cu}$ (II) and $\mathrm{Fe}$ (II) ions. This is a disadvantage for fluorescence sensor systems. However, non-fluorescent $\mathrm{Cu}^{+2}$ and $\mathrm{Fe}^{+2}$ ions' creating complexation with fluorophore groups was hopeful and it was found out that fluorescence could become turn-on sensor against different anion and heavy metal ions [10-12].

Calixarenes are compounds in cyclic structure and can form guest-host complexes with ion-molecules. They have gained great importance in supramolecular chemistry and has a wide application area thanks to these properties. Another factor that has made the calixarenes important is their being functionalized easily over ortho and phenolic oxygen called both "upper rim" and "lower rim". It is used as fluorescence probes in receptor synthesis, showing fluorescence property, by means of these features. Recent studies urge that if the appropriate receptor groups are bound to the calix[n]arene compounds, it can be used as a specific and very suitable fluorescence sensor at the mono molecule level [13-17]. These receptor groups are mostly groups such as anthracene, BODIPY, rhodamine, coumarin, perylene, pyrene, naphthalene. Fluorescence probes that are sensitive to the metal ions were synthesized by derivatizing these groups with calixarene compounds from both phenolic oxygen and para positions [18].

The literature showed that studies of fluorescent probes developed against heavy and transition metal ions and studies based on fluorometric determination management are very common. These studies are mostly about the fluorometric determination of $\mathrm{Zn}$ (II) and $\mathrm{Cu}$ (II) ions in fluorescence-based sensor systems through developing the fluorescent probes that are sensitive to $\mathrm{Zn}$ (II) and $\mathrm{Cu}$ (II) ions. For example, Nam et al. (1999) carried out $\mathrm{NH}_{2}$ transformation of $-\mathrm{NO}_{2}$ groups- in the para position of phenolic rings and examined anion binding properties. What is more, Lee et al. (2005) derivatized the calix[4]arene compounds with azaamide compounds and investigated the complexation features of these compounds against different metal cations and anions. When Lewis acid base interaction of all ions in the periodic table is taken into consideration,it is seen that the ions are divided into two basic classes as hard and soft.The hard definition is used in both acids and bases for atomic ion and molecule whose electron are strongly held by the nucleus and which are diffulcult to electron migration, in the other words, which have low polarity. Additionally, the ions in the class of hard acids must have a high charge and have a small diameter. A similar property may be considered for hard bases. The term soft refers to highly polarizable atoms, molecules, or ions whose electrons are not strongly retained by the nucleus and are easy to migrate to. Hard acids have high energy the lows unoccupied molecular orbital (LUMO) and hard bases have high energy the highest occupied molecular orbital (HOMO).

Density Functional Theory (DFT) is a calculation method deriving the properties of the molecule based on the determination of the electron density of the molecule.Structure of molecules and their spectroscopic characteristics (Geometric optimization, IR, Raman and UV-Vis spectra calculations, energy of molecular structure, transition states energies, atomic charges, molecular orbitals, electrostatic potentials, NMR spectrum, nonlinear optical states and thermochemical properties [19-21], results consistent with experimental data can be obtained in a short time with this method. The accuracy of data obtained experimentally can be easily controlled by computational methods and more clear information about atoms, molecules and ions can be achieved by comparing experimental data with theoretical data.

In this study, we achieved the new type p-terbutylcalix[4]arene derivative compounds by activating benzylisoquinoline derivatives showing fluorescence property and calix[4] arene molecules containing amine group. The fluorescence properties of fluorescence probes that they show by using their activation with some metal ions were examined with instrumental devices such as UV-Vis spectroscopy and fluorescence spectroscopy. In this regard, their fluorescence properties gained by metals and the absorbance properties were compared and thus, it was found out that it could be used as a turn-off sensor. Studies have been verified with theoretical data.

\section{Materials and Methods}

All of the chemicals used in experimental studies were of analytical purity and they were obtained from the companies such as Aldrich, Merck Fluka. Millipore Milli-Q Plus device was used for aqueous solutions to be used throughout the studies. Varian Nuclear Magnetic Resonance $600 \mathrm{MHz}$ spectrometer device was used for the structural characterization of the synthesized original molecules. Measurements were taken at room temperature and in deuteron chloroform solvent. Hitachi F-7000 FL Fluorescence Spectrophotometer and Perkin Elmer UV-Visible spectrometer were used for absorption measurements. 


\subsection{Synthesis and characterization}

The purpose of this study is to synthesize new calixarene-based structures with 1,3-mutual conformation which may form a complex with some metal cations. In accordance with this purpose, starting material 5,11,17,23-ter-butylcalıx[4]arene (1) was first synthesized according to the literature by benefiting the studies in the literature, and thus the reaction was carried out. The methods present in the literature [4]. Synthesized numbered 1 compound was activated by being dissolved in anhydrous acetone in the presence of chloro-acetonitrile, $\mathrm{K} 2 \mathrm{CO} 3$ and $\mathrm{NaI}$ in accordance with the studies in the literature. the 5,11,17,23-tetratert-butyl-25,27-di (cyanomethoxy) -26,28-dihydroxy calix[4]arene compound was obtained. 2 numbered compound was obtained at the end of the reaction in $57 \%$ yield. Obtained nitrile-derived compound was then interacted by strong reducing reagents such as LiAlH4 and amine-derived 5,11,17,23-Tetra-tertbutyl-25,27-di- (aminoethoxy) -26,28dihydroxycycline[4]arene compound was achieved as a white solid in $96 \%$ yield. Calix[4]arene derivatives carrying group were synthesized by interacting the obtained amine derivative calix[4]arene compound 3 with 1,8-naphthalic anhydride and its derivatives in $\mathrm{CHCl} 3$ for 6 hours using the condenser system. As is known, the calixarenes have different conformations such as cone, partial cone, 1,3-reciprocal and 1,2reciprocal. The structure of the synthesized amine group carrying calixarene derivatives was determined by their ${ }^{1} \mathrm{H}-\mathrm{NMR}$ and $13 \mathrm{C}-\mathrm{NMR}$ characterizations (Figures 1, 2, 3).

\subsection{1. $5,11,17,23$-tetra-tert-butyl-25,27-di- (aminoethoxy))-26,28-dihydroxycalix[4] arene}

1 gr $(1.37 \mathrm{mmol})$ of tetra-tert-butyl-25,27-di (cyanomethoxy) -26,28-dihydroxycycline [4] arene compound was taken and dissolved in $50 \mathrm{ml}$ of diethyl ether. $0.43 \mathrm{gr}(11.3 \mathrm{mmol}) \mathrm{LiAlH}_{4}$ was slowly added to the reaction mixture. The reaction mixture was refluxed for 5 hours. The reaction mixture was then poured into ice-water and extracted with $50 \mathrm{ml}$ of benzene and $2 \mathrm{ml}$ of water. The organic phase was separated and dried on $\mathrm{MgSO}_{4}$ and the solvent was removed in rotary evaporator. The product was obtained in the form of a white solid (96\% yield). ${ }^{1} \mathrm{H}$ NMR $\left(\mathrm{CDCl}_{3}\right) \delta 8.31$ (wide s, $\left.2 \mathrm{H}, \mathrm{ArOH}\right), 7.04-6.97$ (two s, 8H, ArH), 4.24 and 3.43 (a pair of d, 8H, $\left.\mathrm{ArCH}_{2} \mathrm{Ar} \mathrm{J}=12.9 \mathrm{~Hz}\right), 4.07$ (t, 4H, $\left.-\mathrm{OCH}_{2}-\right), 3.30$ (t, $4 \mathrm{H},-\mathrm{CH}_{2} \mathrm{~N}$ ), 1.25 and 1.09 (two s, $36 \mathrm{H}$, tert-butyl)
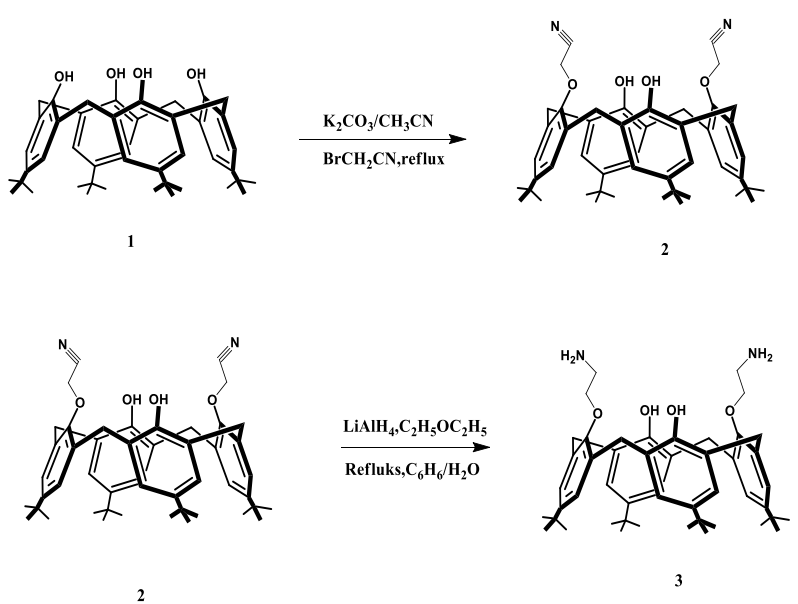

Figure 1. 5,11,17,23-tetra-tert- butyl -25,27-di-( aminoethoxy)-26,28- dihydroxycalıx[4] arene (3) synthesis.

\subsubsection{1,8-calix[4]aren general synthesis procedure carrying the benzylisoquinoline group}

Benzylisoquinoline and its derivatives $(0.01 \mathrm{mmol})$ and the amine-derived calix[4] arene compound $(0.01$ mmol) were dissolved in $60 \mathrm{ml} \mathrm{CHCl}_{3}$ and refluxed for 6 hours. The reaction was terminated as soon as the basic materials finished by performing the reaction follow with TLC. Following the termination of the reaction, it was cooled till the room temperature and the crystals obtained were filtered and dried by adding $250 \mathrm{ml}$ of water on it. The structural characterization of the achieved products was determined by instrumental methods such as ${ }^{13} \mathrm{C}-\mathrm{NMR}$ and ${ }^{1} \mathrm{H}-\mathrm{NMR}$ and the products were obtained in percentages ranging from $70 \%$ to $80 \%$.

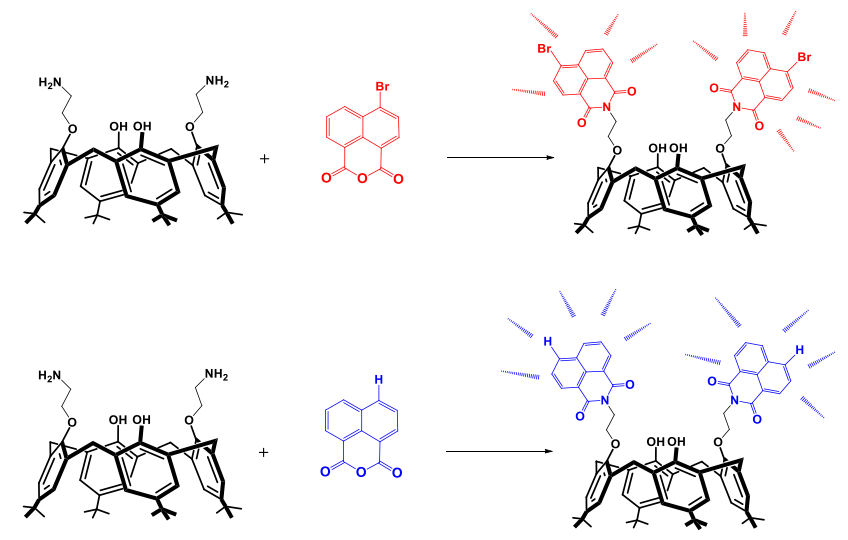

Figure 2. Synthesis stage of calix[4] arene derivative bearing benzylisoquinoline group.

\subsection{Spectroscopic measurements}

$1 \mathrm{~mL} 4.10^{-4} \mathrm{M}$ nitrate solutions of different metal ions were added into $1 \mathrm{~mL}$ of $2.10^{-5} \mathrm{M}$ fluorescent calix[4]arene solution, and then it was mixed for absorbance measurements and shaken at room 
temperature approximately for $5 \mathrm{~min} .1 \mathrm{ml}$ of acetonitrile solution was added to the calix[4]arene solution showing the characteristics of $1 \mathrm{~mL} 2.10^{-5} \mathrm{M}$ fluorescence, and absorption values of the formed solution were examined for blind reading trials to be conducted at UV-Vis spectrophotometer. The samples, which were created by adding the solutions of the different metal ions of these compounds and the new generation calix[4]arene derivatives carrying the synthesized benzylısoquinoline group were scanned at UV-Vis. Spectrophotometer between 200-500 nm wavelengths.

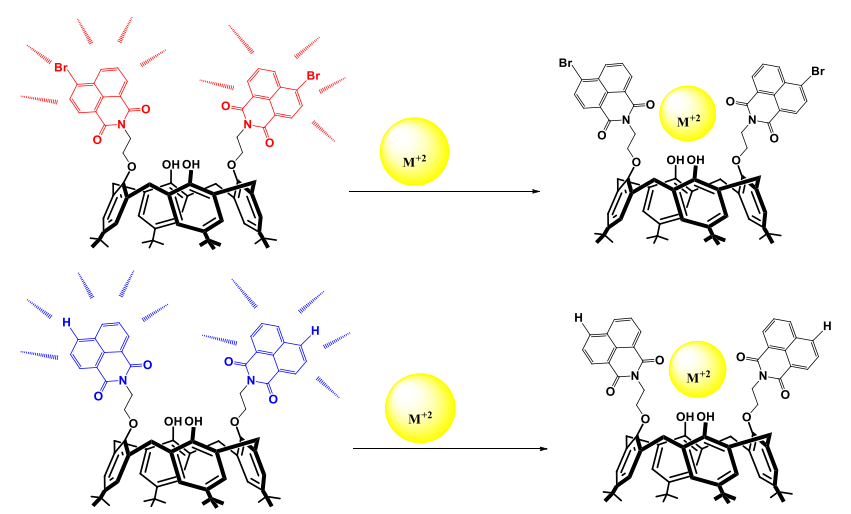

Figure 3. The complex structure of metal ion and calix [4] arene carrying benzylisoquinoline group.

\subsection{Theoretical studies}

The computational studies were carried out by using the GAUSSIAN 16 program in DFT method in order to support the experimental study. 6-31G (d) basis set of B3LYP approach is frequently used in sensor studies for the geometric optimization of the ligand and it was used actively in the study as it provided successful results. The TDDFT/B3LYP function and the LANL2DZ basis set [24-27] was used in the electronic transition calculations for the ligand. Water was preferred asthe solvent environment in all calculations. These calculation values were used in the interpretation of the sensor behaviour of the energy difference value between the highest occupied molecular orbital (HOMO) energy and the lows unoccupied molecular orbital (LUMO) energy and to obtain the UV-Vis spectra.

\section{Results and Discussion}

Calixarenes can be functionalised from p-positions by using chemicals suitable for various purposes thanks to its ring void. In this sense, they have the ability to make metal cations complex with anion and neutral compounds. In this study, calix[4]arene derivatives carrying two different original naphthyl anhydride groups (benzylisoquinoline) in new type with fluorescence characteristics were synthesized. Their structures were confirmed by ${ }^{1} \mathrm{H}-\mathrm{NMR}$ and ${ }^{13} \mathrm{C}-\mathrm{NMR}$ techniques. According to the results obtained, the calix[4]arene compound carrying the H-naphthyl anhydride group was activated with different metal solutions, it was scanned between 200-500 nm wavelength at UV-Vis spectroscopy and it was determined that it gave high absorption with $\mathrm{Cu}^{+2}, \mathrm{Fe}^{+2}$ metals compared to other metal solutions used. In addition, it was understood from the strong absorption peak of the calix[4]arene compound carrying $\mathrm{H}$ benzylisoquinoline that it was strongly bound to $\mathrm{Cu}^{+2}$ metal. It was observed that the $\mathrm{Br}$ - benzylisoquinoline derivative compound gave a high absorption rate which was formed by the addition of different metal solutions and the highest and $\mathrm{Fe}^{+2}$ metal had the highest peak of these. It was understood from the absorption peak it gave that it activated with $\mathrm{Fe}^{+2}$ metal in this compound, but benzylisoquinoline derivative which is $\mathrm{NO}_{2}$ group was a weaker activation compared to calix[4]arene compound.
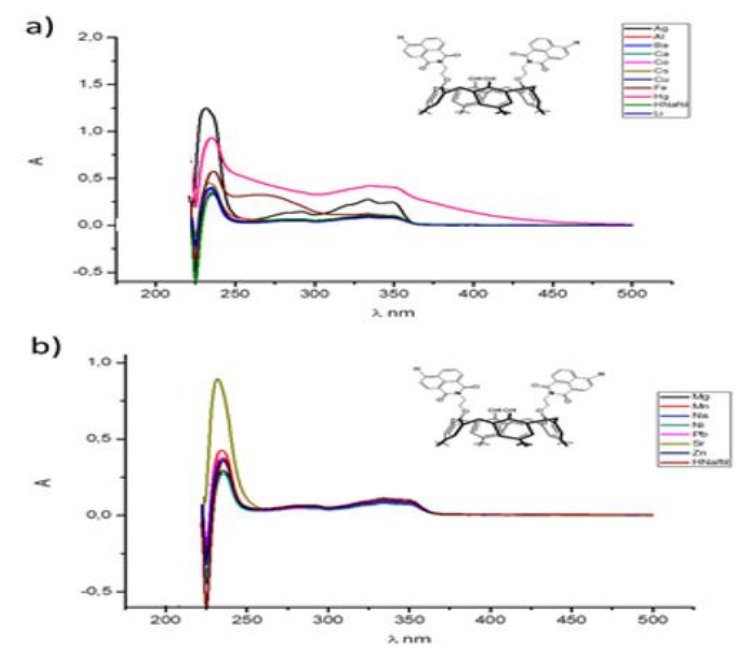

Figure 4. The UV-Vis values of the $\mathrm{H}$ - benzylisoquinoline derivative compound as a result of its interaction with different metals. 

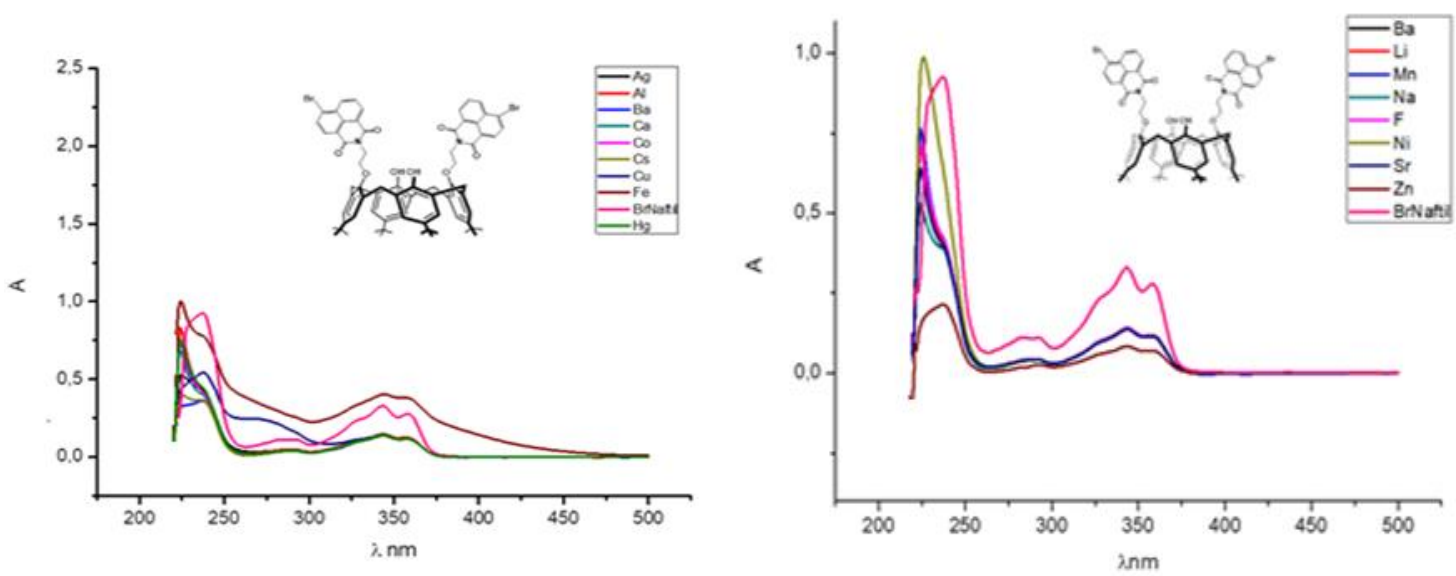

Figure 5. The UV-Vis values of the $-\mathrm{Br}$ benzylisoquinoline derivative compound as a result of its interaction with different metals.

As a result of spectrophotometric measurements of the calix[4]arene compounds carrying 1,4,5,8naphthalethetecarboxylic anhydride group (benzylisoquinoline); it was observed that $-\mathrm{Br}$ benzylisoquinoline derivative compound gave emission peak at $450 \mathrm{~nm}$ when it was induced at $\lambda$ eks $=380 \mathrm{~nm}$, however, decrease, originating from the metal ions, was observed in the spectral values by the addition of different metal solutions used. These ions caused a decline in the monomer emission intensity. As a result of the study, $\mathrm{Fe}^{+2}$ is the ion showing the most extinguishing effect. This may be explained depending on the recycling of the PET mechanism. An electron migration takes place from the aromatic rings of the compound having naphthyl anhydride ring structure towards the other nitrogen atom in the structure and this reduces fluorescence intensity. Moreover, this situation is thought to be a conformation-dependent factor. Metal ions enter the void between anhydride rings in structure with the addition of metal ion solutions into the solution having $-\mathrm{Br}$ benzylisoquinoline molecule in its structure and this causes change in its conformation structure. In this case, the emission intensity decreases.

The fluorescence absorption values obtained by adding $\mathrm{Fe}^{+2}$ ion at different concentrations on the $-\mathrm{Br}$ benzylisoquinoline derivative compound are shown in Figure 7. As can be seen from the absorption values obtained, it was observed that their emission intensities at $450 \mathrm{~nm}$ decreased in parallel with the increase in the concentration of metal ions.

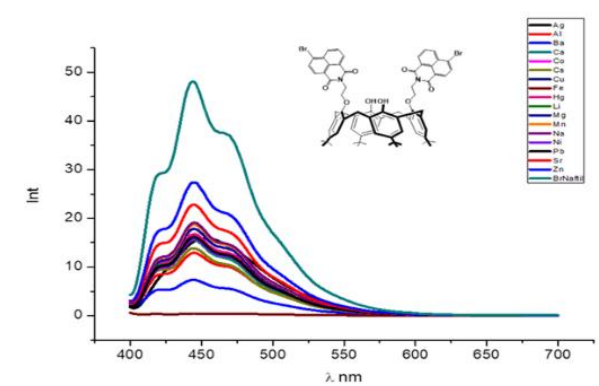

Figure 6 The fluorescence values of the $\mathrm{Br}$ benzylisoquinoline derivative as a result of its interaction with different metal ion solutions $(\lambda \mathrm{eks}=380 \mathrm{~nm})$.

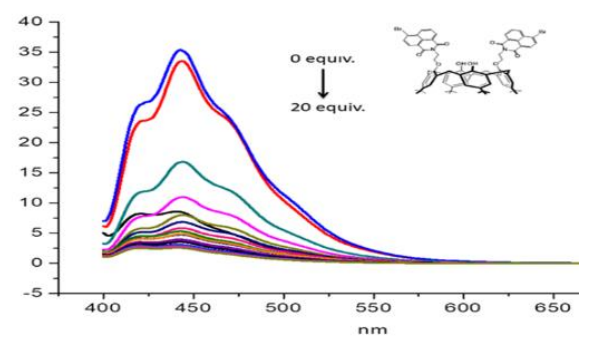

Figure 7. The fluorescence values of the $\mathrm{Br}$ benzylisoquinoline derivative with the addition of $\mathrm{Fe}\left(\mathrm{NO}_{3}\right)_{2}$ ( $0-20$ equiv) in different concentrations $(\lambda \mathrm{eks}=380 \mathrm{~nm})$.

It was seen that $-\mathrm{H}$ benzylisoquinoline derivative compound gave a new emission band at $450 \mathrm{~nm}$ when it was induced at $\lambda \mathrm{eks}=380 \mathrm{~nm}$. When different metal ions were added into the solution of the compound prepared in this way and it was scanned again, the emission intensity increased powerfully but decrease was observed in the emission intensity with the addition of $\mathrm{Fe}^{+2}$ and $\mathrm{Cu}^{+2}$ ions. It was determined that $\mathrm{Cu}^{+2}$ ion had the maximum extinguishing effect. The 
reason for this decrease in the fluorescence emission intensity can be explained with electron transfer of the naphthyl anhydride groups in the cyclic structure towards the nitrogen atoms (reverse-PET) and with the change occurred in its conformation.

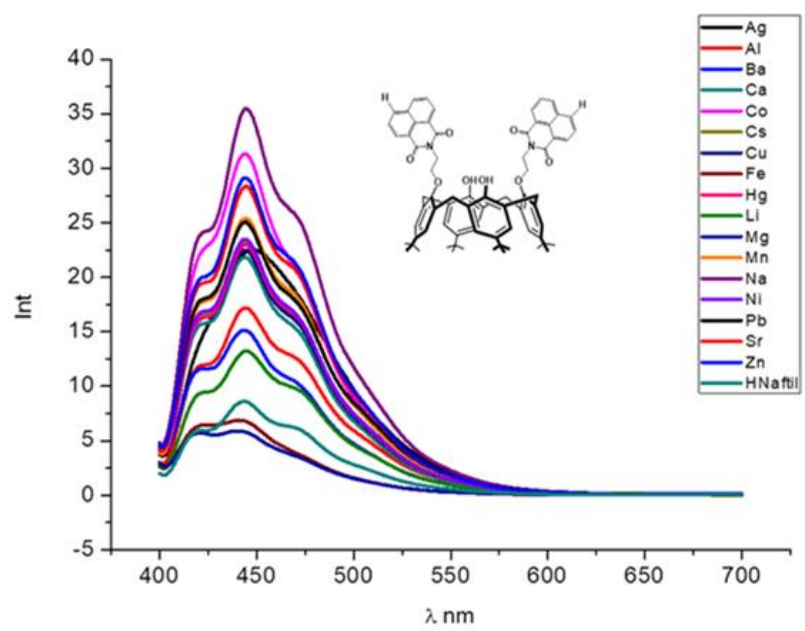

Figure 8. The fluorescence values of the $\mathrm{H}$ - compound as a result of its interaction with different metal ion solutions $(\lambda \mathrm{eks}=380 \mathrm{~nm})$.

\section{Method of Continuous Variations (Job Method):}

The method of continuous variations called Jobs method is generally the metal/ligand ratio in the transition metal complex absorbing light. In other words, it is the determination of the stoichiometric ratio of the formed complex with the wavelength of the absorbed light. If this is explained with an example, a complex is formed between the ligand and any metal ion and the solutions, in which concentration of ligand $[\mathrm{CL}]$ and concentration of metal ion $[\mathrm{CM}]$ and the total of these $[\mathrm{CT}=\mathrm{CL}+\mathrm{CM}]$ are held fixed, are prepared in order to determine its absorbance in the wavelength and the absorbance values of this prepared complex are measured. A new chart is obtained by entering the $\mathrm{VM} /(\mathrm{VM}+\mathrm{VL})$ values into the chart against absorbance values taken, mole fraction of metal ion or ligand. The volume of the VM cation solution gives the volume of the VL ligand solution. The breakpoint of the obtained chart provides the mole fractions, XM/XL, metal ion/ligand ratio in its complex structure. If the complexation constants are 0.5 for ML, 0.33 de ML2,
0.25 de ML3, 0.20, it is determined that there is a complexation of ML4.
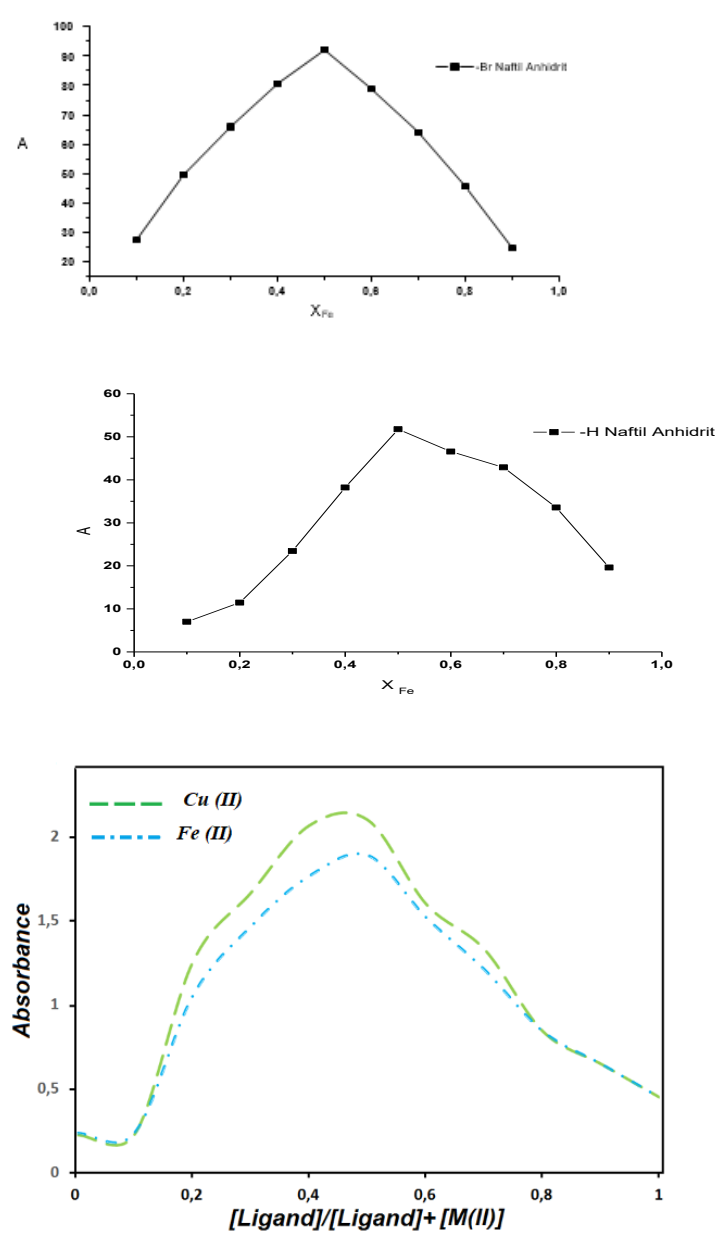

Figure 9 The mole fraction of the complex, which was formed by $-\mathrm{Br}$ benzylisoquinoline calix [4]arene derivative and $-\mathrm{H}$ benzylisoquinoline calix[4]arene derived compound in the presence of $\mathrm{Fe}^{+2}$ ion, against absorbance. 

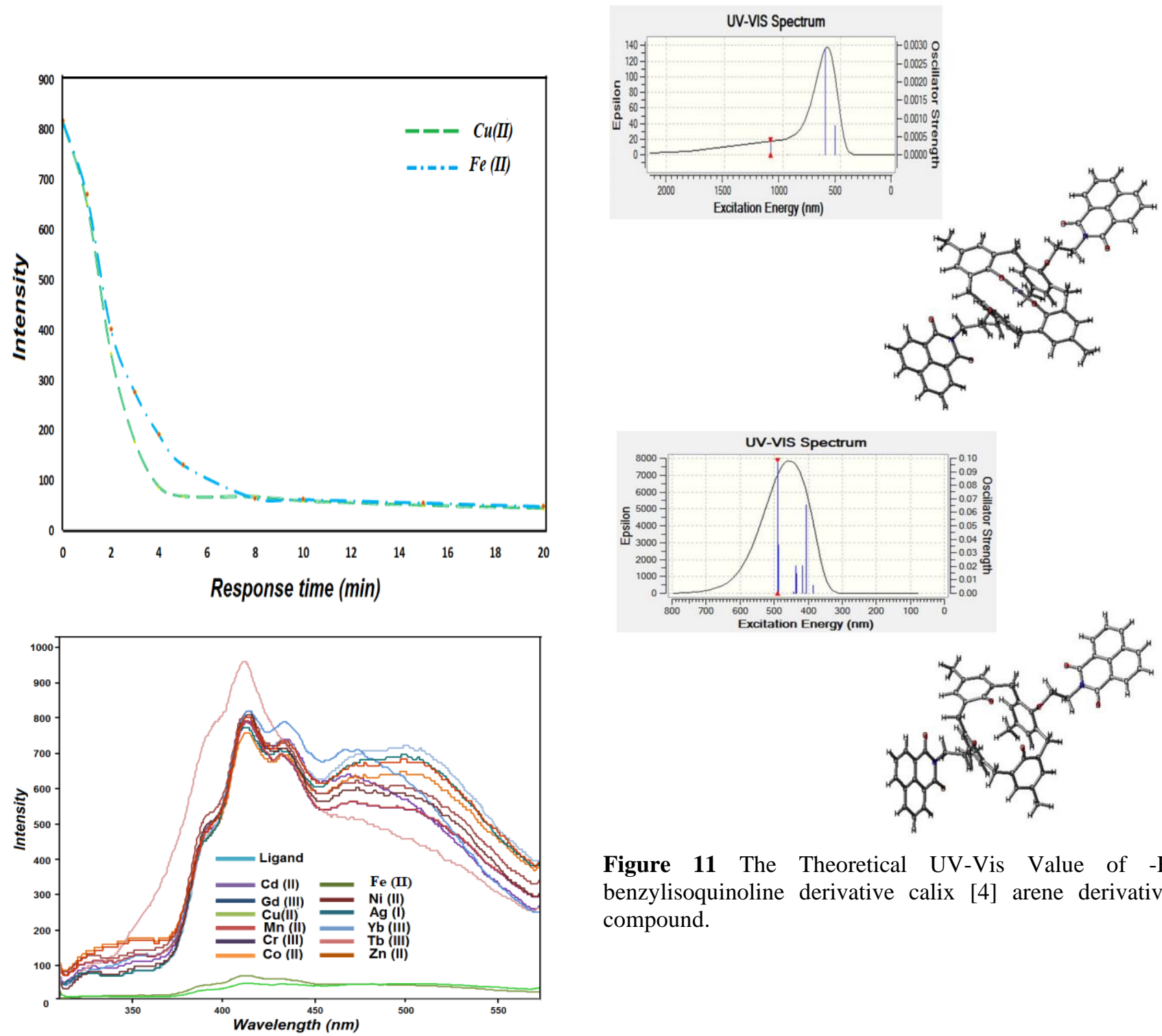

Figure 11 The Theoretical UV-Vis Value of $-\mathrm{H}$ benzylisoquinoline derivative calix [4] arene derivative compound.

Figure 10. The response of prepared ligand solution as fluorescence sensor and absorption changes in fluorescence spectroscopy

\subsection{Theoretical Calculations}

Optimized structure of the compounds of original $-\mathrm{Br}$ benzylisoquinoline derivative calix[4] arene and $-\mathrm{H}$ benzylisoquinoline derivative calix[4]arene is given in figures of 11 and 12. Schematic representation of molecular orbital energies and HOMO-LUMO energy levels and UV-Vis and Fluorescence spectrum values are provided. HOMO-LUMO energy levels are $3.41076 \mathrm{eV}$. To conclude, the theoretical data obtained are consistent with the experimental data. 

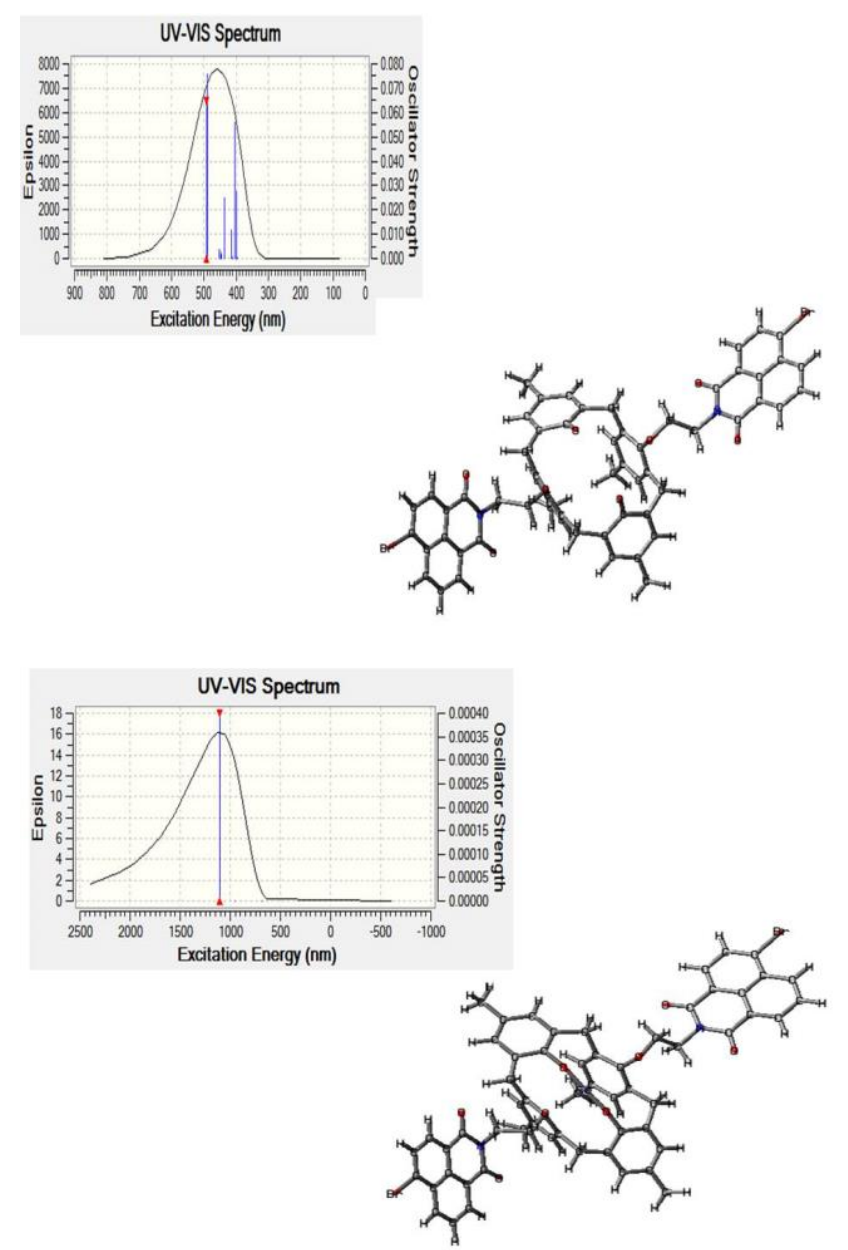

Figure 12. The Theoretical UV-Vis Value of $-\mathrm{Br}$ benzylisoquinoline derivative calix [4] arene derivative compound.

\section{Conclusions}

This study synthesised calix[4]arene derivatives, containing benzo-isoquinoline groups that are not found in the literature. Characterization of synthesized compounds was examined by using ${ }^{1} \mathrm{H}-\mathrm{NMR}$ and ${ }^{13} \mathrm{C}$ NMR spectra. Spectrophotometric and spectrofluorometric measurements of obtained $\mathrm{Br}$ benzoisoquinol and $\mathrm{H}$ - benzylisoquinoline calix [4] arene-derived compounds were carried out in the presence of $\mathrm{Ag}+, \mathrm{Ba}^{+}, \mathrm{Na}^{+}, \mathrm{Li}^{+}, \mathrm{Ca}^{+2}, \mathrm{Co}^{+2}, \mathrm{Cs}^{+2}, \mathrm{Hg}^{+2}$, $\mathrm{Pb}^{+2}, \mathrm{Mg}^{+2}, \mathrm{Mn}^{+2}, \mathrm{Cu}^{+2}, \mathrm{Ba}^{+2}, \mathrm{Ni}^{+2}, \mathrm{Zn}^{+2}, \mathrm{Sr}^{+2}, \mathrm{Al}^{+3}, \mathrm{Fe}^{+3}$ It was found out that when $\mathrm{H}$-benzylisoquinoline group-carrying calix[4]arene compound is activated with different metal solutions, it gave higher absorption with the metals of $\mathrm{Hg}^{+2}, \mathrm{Fe}^{+2}$ compared to other metal solutions used. In addition, it was observed that H-benzylisoquinoline derivative reduced the emission intensity of $\mathrm{Fe}^{+2}$ ve $\mathrm{Cu}^{+2}$ ions significantly compared to other methods in fluorometric measurements and $\mathrm{Cu}^{+2}$ was the ion showing the most extinguishing effect. The highest absorption peak of the $\mathrm{Br}$ - benzylisoquinoline derived compound was achieved especially through $\mathrm{Li}^{+2}$ metal. It was observed that Br-benzylisoquinoline derivative compound gave monomer band at $450 \mathrm{~nm}$ when it was induced at $\lambda \mathrm{eks}=380 \mathrm{~nm}$. It was also observed that when its spectrum was received again by adding metal ions into its solution, $\mathrm{Zn}^{+2}$ ion from the metal ions used increased the monomer emission intensity powerfully while $\mathrm{Fe}^{+2}$ and $\mathrm{Ag}+$ ions decreased the monomer emission intensity. It was detected according to these obtained results that the synthesised new calix[4]arene compounds showed sensor property especially against $\mathrm{Fe}^{+2}$ and $\mathrm{Cu}^{+2}$ ions. $\mathrm{Fe}^{+2}$ and $\mathrm{Cu}^{+2}$ ions are expected to behave as hard acids since their diameters are small and their charges are high. Although these ions act as acceptors when complexing with calix[4]arene compounds.Because the presence of carbonyl groups of the calix[4]arene molecule increases the softness property as it helps to spread electrons along the $\pi$ bonds. $\mathrm{Fe}^{+2}$ and $\mathrm{Cu}^{+2}$ ions are defined as intermediate acids since hard acids tend to react with hard bases and soft acids with soft bases. What is more, these studies and the results obtained indicate that synthesised calix[4]arene compounds showed sensor property and they could be used for the studies to be conducted in this field.

\section{References}

[1] Li Q., Guo Y., Shao S., A BODIPY based fluorescent chemosensor for $\mathrm{Cu}(\mathrm{II})$ ions and homocysteine/cysteine, Sens. Actuators B: Chem., 171 (2012) 872-877.

[2] Martinez R., Espinosa A., Tarraga A., Molina P., A new bis(pyrenyl)azadiene-based probe for the colorimetric and fluorescent sensing of $\mathrm{Cu}(\mathrm{II})$ and $\mathrm{Hg}(\mathrm{II})$, Tetrahedron, 66 (2010) 36623667.

[3] Gao Y., Li Y., Yang X., He F., Huang J., Jiang M., Zhou Z., Chen H., Design, synthesis and biological evaluation of a novel $\mathrm{Cu}^{2+}$ selective fluorescence sensor for bio-detection and chelation, RSC Adv., 5 (2015) 80110-80117.

[4] Gutsche C.D., Iqbal M., Stewart D., Calixarenes 19 Synthesis Procedures for p-tert Butylcalix[4]arene, J. Org. Chem., 51 (1986) 742.

[5] Dujols V., Ford F., Czarnik A.W., A longwavelength fluorescent chemodosimeter selective for $\mathrm{Cu}(\mathrm{II})$ ion in water, J. Am. Chem. Soc., 119 (1997) 7386-7387. 
[6] Xiang Y., Tong A., Jin P., Ju Y., New fluorescent rhodamine hydrazone chemosensor for $\mathrm{Cu}(\mathrm{II})$ with high selectivity and sensitivity, Org. Lett., 8 (2006) 2863-2866.

[7] Valeur B., Leray I., Design principles of fluorescent molecular sensors for cation recognition, Coord. Chem. Rev., 205 (2000) 340.

[8] Moczar I., Peragovics A., Baranyai P., Toth K., Huszthy P., Synthesis and fluorescence studies of novel bis(azacrown ether) type chemosensors containing an acridinone unit, Tetrahedron, 66 (2010) 2953-2960.

[9] Kumar M., Babu J.N., Bhalla V., Kumar R., Ratiometric/on-off sensing of $\mathrm{Pb}^{2+}$ ion using pyrene-appended calix[4]arenes, Sens. Actuators B: Chem., 144 (2010) 183-191.

[10] Grabchev I., Chevelon J.M., Qian X., Polyamidoamine dendrimer with peripheral 1, 8-naphthalimide groups capable of acting as a PET fluorescent sensor for metal cations, New J. Chem., 27 (2003) 337-340.

[11] Sivaraman G., Sathiyaraja V., Chellappa D., Turn-on fluorogenic and chromogenic detection of $\mathrm{Fe}$ (III) and its application in living cell imaging, J. Lumin., 145 (2014) 480-485.

[12] Sirilaksanapong S., Sukwattanasinitt M., Rashatasakhon P., 1,3,5-Triphenylbenzene fluorophore as a selective $\mathrm{Cu}^{2+}$ sensor in aqueous media, Chem. Commun., 48 (2012) 293-295.

[13] Sahin O., Yilmaz M., Synthesis and fluorescence sensing properties of novel pyrenearmed calix[4]arene derivatives, Tetrahedron, 67 (2011) 3501-3508.

[14] Ocak U., Ocak M., Bartsch R.A., Calixarenes with dansyl groups as potential chemosensors, Inorg. Chim. Acta, 381 (2012) 44-57.

[15] Tilki T., Sener I., Karc1 F., Gulce A., Deligoz H., An approach to the synthesis of chemically modified bisazocalix[4]arenes and their extraction properties, Tetrahedron, 61 (2005) 9624-9629.

[16] Akkus G.U., Memon S., Sezgin M., Yilmaz M., Synthesis of calix (aza) crown and its oligomeric analogue for the extraction of selected metal cations and dichromate anions, Clean-Soil, Air, Water, 37 (2009) 109-114.
[17] Patra S., Lo R., Chakrabort A., Gunupuru R., Maity D., Ganguly B., Paul P., Calix[4]arene based fluorescent chemosensor bearing coumarin as fluorogenic unit: synthesis, characterization, ion-binding property and molecular modeling, Polyhedron, 50 (2013) 592-601.

[18] Erdemir S., Tabakci B., Tabakci M.A., Highly selective fluorescent sensor based on calix[4]arene appended benzothiazole units for $\mathrm{Cu}^{2+}, \mathrm{S}^{2-}$ and $\mathrm{HSO}_{4}^{-}$ions in aqueous solution, Sens. Actuators B: Chem., 228 (2016) 109-116.

[19] Kumar R., Bhalla V., Kumar M., $\mathrm{Cu}^{2+}$ and $\mathrm{CN}^{-}$ selective fluorogenic sensors based on pyrene appended thiacalix[4]arenes, Tetrahedron, 64 (2008) 8095-8101.

[20] Bayrakci M., Ertul S., Yilmaz M., Synthesis of di-Substituted calix[4]arene-based receptors for extraction of chromate and arsenate anions, Tetrahedron, 65 (2009) 7963-7968.

[21] Frisch M.J.E.A., Trucks G.W., Schlegel H.B., Scuseria G.E., Robb M.A., Cheeseman J.R., Nakatsuji H. Gaussian 09, Gaussian Inc., Wallingford CT, 2009; pp 200.

[22] Deligoz H., Ercan N., The synthesis of some new derivatives of calix[4] arene containing azo groups, Tetrahedron, 58 (2002) 2881-2884.

[23] Vysotsky O.M., Bohmer V., Wurthner F., Calix[4]arene-functionalized naphthalene and perylene imide dyes, Org. Lett., 4 (2002) 29012904.

[24] Foresman J.B., Frish E., Exploring chemistry with electronic structure methods, Gaussian, Inc., Pittsburgh PA, USA, 1996; pp 253.

[25] Habib U., Anwar-Ul-Haq A.S., Salma B., Khurshid A., DFT study of polyaniline NH3, $\mathrm{CO}_{2}$, and $\mathrm{CO}$ gas sensors: comparison with recent experimental data, J. Phys. Chem. C, 117 (2003) 23701-23711.

[26] Habib U., Anwar-Ul-Haq A.S., Salma B., Khurshid A., Doping and dedoping processes of polypyrrole: DFT study with hybrid functionals, J. Phys. Chem. C, 118 (2014) 17819-17830.

[27] Lee M.H., Quang D.T., Jung H.S., Yoon J., Lee C.H., Kim J.S., Ion 1nduced FRET on-off in fluorescent calix[4]arene, J. Org. Chem., 72 (2007)4242-4245. 